\title{
Creating learning solutions for executive education programs
}

Article

Accepted Version

Creative Commons: Attribution-Noncommercial-No Derivative Works 4.0

Dover, P. A., Manwani, S. and Munn, D. (2018) Creating learning solutions for executive education programs.

International Journal of Management Education, 16 (1). pp. 80-91. ISSN 1472-8117 doi:

https://doi.org/10.1016/j.ijme.2017.12.002 Available at https://centaur.reading.ac.uk/88066/

It is advisable to refer to the publisher's version if you intend to cite from the work. See Guidance on citing.

To link to this article DOI: http://dx.doi.org/10.1016/j.ijme.2017.12.002

Publisher: Elsevier

All outputs in CentAUR are protected by Intellectual Property Rights law, including copyright law. Copyright and IPR is retained by the creators or other copyright holders. Terms and conditions for use of this material are defined in the End User Agreement.

\section{www.reading.ac.uk/centaur}

\section{CentAUR}

Central Archive at the University of Reading 
Reading's research outputs online 


\section{Creating Learning Solutions in Executive Education Programs}

\section{Philip Dover (Babson College) and Sharm Manwani (Henley Business School)}

\section{INTRODUCTION}

An Association of Talent Development (ATA) 2013 State of the Industry report estimated that US organizations spent approximately $\$ 164.2$ billion on employee learning and development in 2012. Of this total direct learning expenditure, $61 \%$ (\$100.2 billion) was spent internally. The remainder was spent on external services, which accounted for $28 \%$ ( $\$ 46$ billion), and tuition reimbursement, which accounted for $11 \%$ ( $\$ 18$ billion). Of this more than $\$ 60$ billion external services expenditure (globally estimated at around $\$ 135$ billion), greater than $50 \%$ was accounted for by technology, tools and other "non-instructor led" activities. ${ }^{1}$ Research by Deloitte (2015) shows that the principal area of spending on corporate training is in management and leadership (35\%) ${ }^{2}$. Putting aside tuition reimbursement (mainly applied to MBA and similar professional degree programs), we must pose the question of whether the remaining (and growing) institutional investment on business education is well spent? We propose that this depends on whether well-articulated program objectives and metrics used to assess program performance are met. Tushman et al. (2007) - adapting some earlier work by Kirkpatrick (1994) and Phillips (2003) - indicate that program impact should be measured through individual learning, individual behavioral change, organizational change and organizational results. In order to assess such outcomes, individuals were questioned on a) their motivation for attending an executive education program, b) their preparation prior to attending, c) their application of learnings/concepts/methodologies since attending the course, d) the depth of their knowledge post-program, and e) the behavioral change/transfer that had occurred. Tushman et al., also found that organizational results (e.g., increased revenue) were considerably stronger when custom programs where collaboratively designed by company executives and business school faculty, utilized action-based projects and recruited program participants as in-tact teams.

Given the growing expenditure on executive education, what proportion of companies conscientiously measure the benefits of their investments? Ann Ruddy of World at Work speculates that "I think less than $10 \%$ of organizations have any serious quantitative way of

\footnotetext{
${ }^{1}$ It has proved difficult to distinguish between "learning and development" and "executive education." Similarly, it is hard to assess the approximate level of external educational services undertaken by business schools. An early Business Week reference (2001) suggested that about $80 \%$ of executive education programs were accounted for by business schools although this is likely to have shrunk considerably with the advent of for-profit educational institutions as well as the emergence of aggressive and focused consultants.

${ }^{2}$ The Deloitte research indicated that of the external learning and development services provided, $22 \%$ went to purchase off-the-shelf content and $15 \%$ to the development of custom e-learning content. Additionally, overall training spending has increased by between 10 and 15\% per year from 2011 to 2014.
} 
saying, 'Gee, we spent this much on this executive, and here's the ultimate return on investment we have."'3 However, this situation is changing as companies become increasingly conscious of the need to ensure that executive investment dollars are efficiently and effectively benefitting both employees and the company, especially as a recent report shows the mean training budget at almost $6 \%$ of payroll in leading organizations for employee development. ${ }^{4}$ How then can program designers and deliverers build carefully considered input-output models for executive education while avoiding the pernicious practices of programs resulting in oneway, faculty driven offerings or short-term perks for over-worked or under-motivated employees?

Let's start by categorizing executive education. We can think of programs in a number of ways. These may include the following classifications that are to some extent linked:

Customer Need and Perceived Value - e.g., functional knowledge vs. issue-based - an example of the former may be a program on Finance for Non-Financial Managers while the latter might offer insights into Banking Challenges in the Digital Age. Resolving specific issues within a program is likely to provide participants with higher perceived value.

Target audience - e.g., individuals vs. teams - There is a tendency to create in-tact teams to explore very specific company issues around which a learning and business impact environment can be created (e.g., a program involving cross-functional members of a venture group charged with devising a business unit innovation strategy).

Delivery Offering: Open enrolment vs. customized - open programs are driven largely by horizontal functional and/or cross-functional content (e.g., Strategic Market Planning across all industries) and, on occasions, vertical content (Strategic Market Planning within Life Sciences). In each case, participants may attend from multiple companies. Customized programs are invariably vertical and offered to all or part of a single company (e.g., Strategic Market Planning issues within the medical device unit at GE) or a networked group of companies/organizations.

By delivery mechanism - a) Teaching approach: a sample continuum may involve lecture $\rightarrow$ case study $\rightarrow$ role play/simulation $\rightarrow$ action-based project. These tools tend to become increasingly individual company relevant as we move to the right (although there is a growing trend towards writing company-specific cases for use within customized programs). b) Remote vs. In-person: The choice of delivery mechanisms has been further compounded by the advent of distance learning, be it fully on-line or blended (a mixture of on-line and face-to-face). Forbes (Bersin, 2014) note that while people still need formal classroom education, this is now less

\footnotetext{
${ }^{3}$ Recorded by Anne Ruddy, President of World at Work, a non-profit association of HR professionals. The quote appeared in Crain's Chicago Business in January, 2011.

${ }^{4}$ http://skilledup.com/insights/how-top-companies-make-the-roi-case-for-employee-training (Jan, 2014)
} 
than half the total "hours" consumed in training around the world. Among the most highly advanced companies, as much as $18 \%$ of all training is now delivered through mobile devices.

Traditional business schools must work very hard to retain relevance in the current and near future executive education climate. As Lorange (2005) points out, corporate audiences now have much more choice of program providers, including for-profit institutions (e.g., Kaplan; Duke Corporate Education) and specialist consultants (e.g., Center for Creative Leadership). ${ }^{5}$ He believes that the modern, visionary business school will evolve into a networked entity (inside and outside the academic fraternity), conducting cutting edge, thought leadership research undertaken by cross-functional and often cross-institutional teams. Such research will be "quickly added to the teaching agenda" to provide state-of-the art knowledge in the executive classroom. The remaining business schools and their faculty must develop a range of new or modified capabilities to respond to these challenges.

This inevitably leads us to a series of questions about how business schools can best understand and respond to client needs in a rapidly changing and increasingly complex environment (globalization; digitalization; technology disruption; "big data" etc.). Specifically, this paper addresses three key questions from a conceptual perspective and develops an appropriate methodological tool that allows a real-world response to these challenges. We then explore the applicability and validity of this tool through an illustrative case study.

\section{TOWARDS A SOLUTIONS-BASED EXECUTIVE EDUCATION FRAMEWORK}

The broad questions addressed in this paper are:

1. What are the evolving characteristics of the executive education market?

2. What are the enhanced capabilities required to successfully deliver executive education programs from both an individual and institutional point-of-view?

3. How should we best evaluate complex executive education programs?

\subsection{Market Characteristics}

We represent the executive education market on two axes -- the level of customer specificity (target audiences) and the nature of customer needs (see Figure 1). We have

\footnotetext{
${ }^{5}$ Duke Corporate Education was ranked \#1 for custom programs in 2013 in Bloomberg Business Week while the Center for Creative Leadership was ranked \#4 overall in the 2016 Financial Times Executive Education ratings.
} 
adapted this diagram from ITSMA, a sales and marketing consultancy ${ }^{6}$ with a long history of working in the "business solution" space. The diagonal bubbles relate to a combination of the delivery methods selected and the supporting tools employed. This provides a more sophisticated program differentiation than binary options such as open vs customized or horizontal vs vertical.

Figure 1. Applying a Solutions-Hierarchy Approach to Executive Education Programs

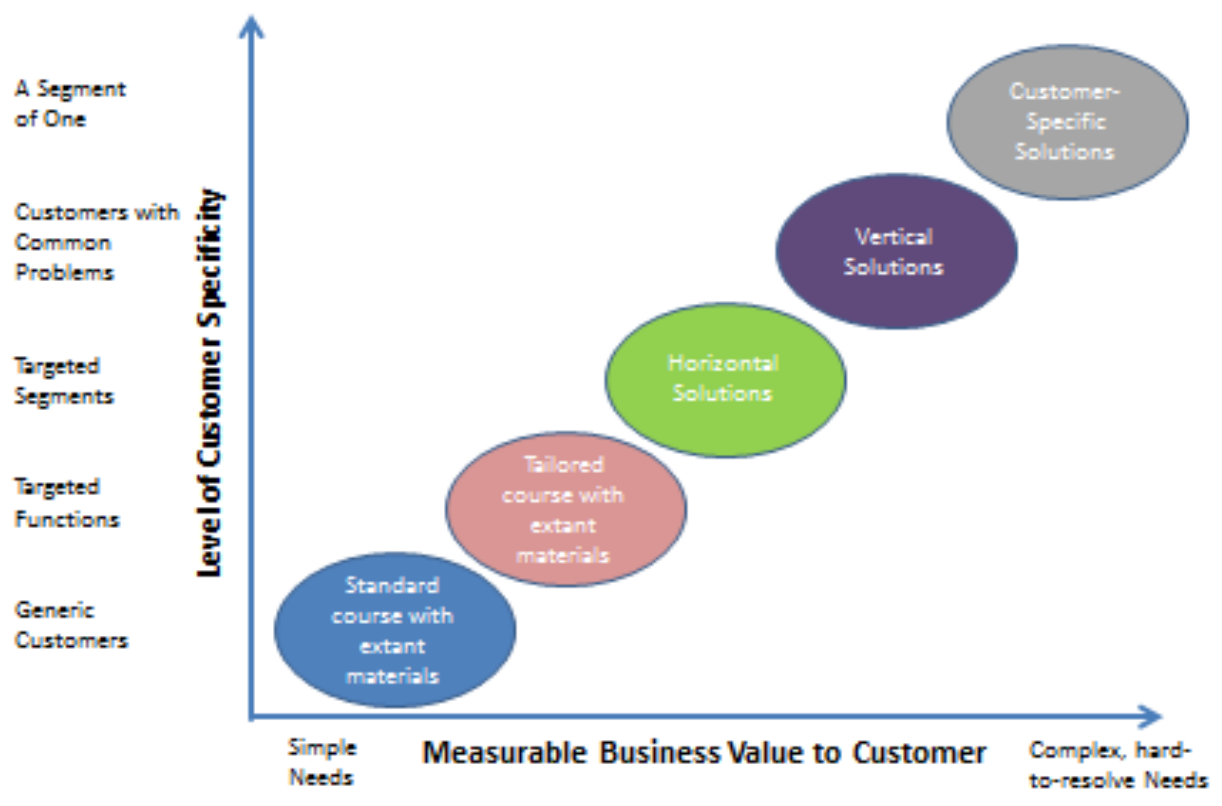

Source: Adapted from http://www.itsma.com/research/itsmas-solutions-taxonomy/

Customer specificity ranges from a broad, largely undifferentiated grouping of firms/individuals all the way through to a unique segment of one. Customer needs relate to the nature of the underlying educational problem and extend from straightforward (e.g., understanding financial statements) to complex, often intractable issues (e.g., build and execute strategy in volatile,

\footnotetext{
${ }^{6}$ ITSMA - who generated much of the conceptual thinking about solutions used in this paper - provides market research, education and advisory guidance on marketing and sales topics to leading B2B companies. More details can be found at www.itsma.com
} 
vertical markets). The extent to which a customer need is met can be represented by the measurable business value provided by the educational experience.

We posit this combination of customer characteristics and needs results in five forms of executive education offerings that span a range from standard products (courses) to highly specific customer solutions. Selecting an approach for executive program design should be a function of a) program objectives and expected outcomes, and b) a careful cost/benefit analysis that weighs resource inputs (time, money, etc.) against desired, measured results (participant learning; firm knowledge applications and subsequent ROI, etc.). How best then to create an appropriate framework to guide such decisions?

We would like to advance the notion of "solutions" as both a conceptual and operational approach to executive education. The idea of the design, delivery and marketing of solutions has become increasingly prominent as a means of adding customer value in both B2B and B2C companies (see, for example, Davies, Brady and Hobday, 2006, Gulati, 2007, Tuli et al., 2007, Dawar, 2013) although there is limited evidence to date of the explicit application of a rigorous solutions perspective within the world of executive education. Where the concept has been used (for instance in the Center for Creative Leadership's "Global Pharmaceutical Leadership Solutions" ${ }^{\prime 7}$ ) the emphasis has largely been on dealing with vital industry specific issues (e.g., cross-functional/multidisciplinary creative collaboration). Important as this work is, we believe it could be extended by assessment of the broad business impact of the learning intervention. Such measurement will likely involve considerable post-program activity.

What then is a "solution?" ITSMA has evolved the following definition:

\section{"A solution is a combination of products and/or services with intellectual capital, focused on a} particular customer problem or opportunity that drives measurable business value."

Applying this to executive education, we can visualize a business school employing its unique intellectual assets and support services (e.g., facilities) to resolve a complex client problem through tailored education/learning with resultant measurable outcomes (new executive capabilities; application of learned concepts/tools to company activities, etc.). Returning to Figure 1, it is helpful to first establish a hierarchy of situations based on a company's core learning and application needs. Each level represents gradually increasing levels of specificity, cost, maturity and complexity. Let's apply these classifications to types of executive education programs.

a) Generic customers with straightforward customer needs and fairly low requirement for measurable business value - most likely open enrolment programs (e.g., Finance for

\footnotetext{
${ }^{7}$ http://www.ccl.org/Leadership/landing/pharm/index.aspx
} 
Non-Financial Executives) where participants learn basic tools, for instance, around financial reporting. Often there is little or no built-in program application to issues faced by the participants' own company issues.

b) Targeted functions (e.g., Marketing) with some limited measurable business value again likely to be open enrolment programs (e.g., Finance for Marketing Executives) where participants learn function specific applications (e.g., sales and marketing implications of the Income Statement). There will be some application of tools to the participants' own company issues.

c) Targeted segments (e.g., Business Development professionals) with moderate measurable business value and well-defined customer needs - these will be mainly open enrolment programs involving horizontal solutions (e.g., CRM for Business Development personnel) where extant business challenges (e.g., data mining; social media) are explored across industries. Largely generic examples will be used although opportunities exist for application to participants' own company issues.

d) Customers with common problems with high measurable business value will require vertical solutions - these could be either open enrolment or customized programs (e.g., CRM applications for the pharmaceutical industry) where participants apply program learnings to industry and company specific issues. Evaluative measures are likely to revolve around business impact within their own firm (e.g., results from action-based learning projects on CRM).

e) A segment of one (a single company, company sub-unit, or even a specific individual) with a complex learning problem linked to a highly measurable business value - this will definitely call for a customized vertical solution (e.g., establishing a CRM System for Medical Devices at GE) where participants frequently undertake company relevant business projects. Program value-measures should certainly focus on post-program business impact.

It is argued that a solutions-based approach to executive education programs will be most impactful at stages d) and e) - that is, where there is a requirement for deep vertical market knowledge, the existence of a complex company challenge, the need for significant intellectual input in program design and delivery from both faculty and client, and the careful measurement of both short and long-term program impact. The positioning of the service provider is further enhanced if the program "solution" is perceived as unique (or at least very hard to replicate) by the client.

These characteristics of solutions can not only provide high impact but also present high complexity. This means that they are high risk for executive education suppliers - as we will see -- if they do not have the required capabilities. 


\subsection{Building Design and Delivery Capabilities}

ITSMA has devised an integrated Solutions Roadmap that allows organizations both to move through a number of stages to eventual solutions mastery while appreciating the capabilities required to execute solutions effectively (Maira and Koch, 2009). We believe this model may be comfortably adjusted to the adoption of a solutions perspective within the world of executive education. The modified Roadmap is as follows:

Figure 2. Solutions Roadmap

\begin{tabular}{|c|c|c|c|c|}
\hline Starting Point & Level 2 & Level 3 & Level 4 & Level 5 \\
\hline $\begin{array}{l}\text { Opportunistic } \\
\text { Solutions }\end{array}$ & $\begin{array}{c}\text { Solutions } \\
\text { Repeatability }\end{array}$ & $\begin{array}{l}\text { Coordinated } \\
\text { Planning }\end{array}$ & $\begin{array}{l}\text { Process } \\
\text { Excellence }\end{array}$ & $\begin{array}{l}\text { Solutions } \\
\text { Mastery }\end{array}$ \\
\hline $\begin{array}{c}\text { Sell mostly } \\
\text { discrete offerings }\end{array}$ & $\begin{array}{c}\text { Leverage } \\
\text { opportunistic } \\
\text { solution successes }\end{array}$ & $\begin{array}{c}\text { Create solutions } \\
\text { center of } \\
\text { excellence }\end{array}$ & $\begin{array}{l}\text { Institutionalize } \\
\text { solution } \\
\text { processes }\end{array}$ & $\begin{array}{c}\text { Embed solutions into } \\
\text { the product and } \\
\text { service development } \\
\text { processes }\end{array}$ \\
\hline & Key Cate & ries of Solutio & lastery & \\
\hline
\end{tabular}

Source: http://www.itsma.com/research/stages-of-solutions-maturity/

The journey to deep solutions expertise often begins with the development of an isolated, opportunistic executive education program that is driven by clients seeking more business value than a traditional learning option (e.g., seeking longitudinal benefits from tailored programs). Similarly, providers begin to see solutions as an opportunity to use their intellectual capital as a long-term opportunity for higher incremental revenue, profit and share of wallet. However, most organizations fail to understand the scope and depth of changes needed to move beyond the opportunistic stage of solutions competence. An explanation of the organizational progression from "Opportunistic Solutions" to "Solutions Mastery" is contained in Appendix A. We argue that there are at least five areas of focus for building an efficient, effective educational solutions delivery capability. These $a^{8}{ }^{8}$ :

\footnotetext{
${ }^{8}$ For an extended discussion of these levers of change in the transition to solutions see Dover and Schwartz, "Are Solutions the Solution to Adding Customer Value?" (2013)
} 
Organizational Design - this will include questions of solutions governance (e.g., centralized within a customized program office), appropriate measurement metrics (aided by separating solutions P\&L responsibility from that of other programs), cross-functional and cross-divisional pre- and post-program integration, design and delivery collaboration with clients and external partners (such as the formation of a Solutions Council), and the appointment of a senior administrator and/or faculty member as the solution's "champion."

Marketing Activities - "deep" knowledge of market trends and client needs are required to identify and design complex program solutions. Such analysis leads to the strategic decisions of program goal formation, target audience selection and program positioning. Faculty with this "deep" market understanding are also essential to lead/guide the cross-functional, solutions cocreation teams, as well as being involved in program delivery and instrumental in post-program assessment.

Portfolio Management - any business school is likely to have a portfolio of executive education programs. Like any portfolio, most schools are looking for a balance of offerings (e.g., new, innovative, high potential programs relying on support from mature, repetitive legacy programs). In reality, few business schools are willing to abandon their traditional program offerings for a pure solutions approach. In many cases, solutions are - and will continue to be a smaller part of the overall portfolio. Consequently, particular attention needs to be paid to systematic solutions development and launch, selection of internal and external strategic partners, and the determination of solutions metrics (participant knowledge retention and improved productivity, institutional business impact outcome, etc.).

Sales and Sales Enablement - in order to sell educational solutions to clients, a more sophisticated approach to the sales function is demanded. Higher sales costs than usual are to be expected as the independent sales person (often the business development manager) is replaced by a sales team (that includes faculty subject experts), compensation is adjusted to account for the greater complexity of solutions (e.g., from volume to margin calculations over a longer sales cycle) and greater integration is demanded between sales and marketing to optimize the whole client experience (i.e., from initial problem recognition to solution replication) through careful "touch point" management. It is hoped, of course, that satisfied clients will become solution advocates.

Culture and Behavior - solutions require deep changes in individual and organizational culture and behavior (e.g., a shift from short-term profit maximization to long-term relationship building). It is often the "people" concern that is the greatest barrier to shifting to a solutions modus operandi (see Schwartz and Hurley, 2012). Critical here is the facilitating role of the CEO/Dean and other top level executive/faculty in both the client and supplier institutions. Often they do not communicate their support enough for detailed, longitudinal educational 
problem solving or with sufficient clarity of vision to move the organizations to a more solutions-oriented mindset. Note that business schools are unlikely to make the transition to solutions via internal training of their own personnel alone. It will often require bringing in new talent with new skills from outside the institution (e.g., adjunct faculty with prior consulting experience; business development personnel who have transitioned from product/service sales to solutions enablement). Making and delivering the solution sale also needs support functions (e.g., legal counsel) to adopt flexible behavior. Think, for example of the IP challenge. It is unlikely that creative solutions will evolve unless clients are prepared to share company confidential data and faculty be willing to employ proprietary concepts and methods.

Moreover, establishing the "boundaries for sharing" increases as the solutions team is made up of, say, faculty from more than one business school.

\subsection{Evaluating Programs}

Our goal has been to make a prima facie case for a solutions framework forming a structured approach to executive education design, delivery and assessment. Within this, decision makers can use the Solutions Hierarchy to determine the level of program customization required (i.e., specificity of customer needs $x$ measurable business value to the customer) and the Solutions Roadmap to assess the type and nature of enablers (organizational design, marketing activities, etc.) needed to produce effective/impactful executive programs. Using the building blocks of our solutions definition - in-depth understanding of client's underlying "problems," use of our educational products, services and intellectual capital to uniquely resolve these "problems," and the establishment of measurable business outcomes from program implementation - we can ask the question "how well are executive education providers meeting the various short and long-term needs of clients?" If we combine these thoughts on solutions with Phillip's (2003) longitudinal framework for evaluating educational outcomes, we can generate a series of questions to ask Schools of Executive Education as to the rigor and productivity of their program practices. These would include:

-- Program objectives - these should be based on a careful determination of client needs. It would be instructive to establish the methodology used for assessing learning needs and the extent to which (if at all) the business school is involved in this problem identification stage. Who is involved in the company and/or business school in the need/problem identification (e.g., HR vs. line management at the firm; business development vs. faculty at the b-school)? What types of goals are established for the program (individual vs. organizational learning/change, short vs. longer-term personnel/business impacts, qualitative vs. quantitative metrics, etc.)? A useful starting point may be to look - where appropriate -- at the RFP's provided at the outset of the process. 
-- Program design - if we are guided by the Solution Roadmap enabler's we can assess a number of important steps in program formulation. Examples would be: the composition and responsibilities of the design team; the stages within the solutions development process; the fit of solution's activities into the overall educational program portfolio management of the client; collaboration with external partners (see Anderson's Platform Model, 2010 ${ }^{9}$ ); and creation of customized, action-based materials. The extent to which these activities may be happening could, in part, be assessed through careful content analysis of business school proposals to clients for customized programs.

-- Program metrics - how do we assess the impact of an executive education program? Traditionally, neither the business school nor the client has gone much beyond measuring participant's short term reaction (i.e., satisfaction with the program). A solutions perspective demands a much deeper analysis of cognitive and behavioral program outcomes - nontransitory changes in knowledge, skills and attitudes (individual learning), the application, implementation or utilization of program content/desired behavior (individual behavior change), changes in business impact indicators linked to the program (organizational change), and a comparison of program benefits, in terms of monetary value, with the financial cost of the program (ROI). The intention to collect such metrics, plus the methodology for doing so, should be contained within the original program proposal.

It should be clear that a solutions-based approach to executive education demands active, longitudinal co-creation and involvement from both clients and providers. Any research program to assess such a solutions orientation should involve extensive data collection from both parties. The next section describes our early efforts to observe an example of the processes used in designing and delivering an executive education program across the solutions spectrum.

\section{CASE-BASED APPROACH - METHOD AND LEARNINGS}

The lack of prior research on executive education program development and the desire to explore the viability of a new "solutions-based" framework led us to critically assess a recent program that could be classified as a highly customized offering. A content analysis was undertaken with two main initial goals:

\footnotetext{
${ }^{9}$ The Platform Model for executive learning (Anderson and van Wijk, 2010) is based on the existence of a 2-sided network. On one side of this network are the individuals and firms that possess specialist skills and expertise, and on the other are organizational clients seeking learning solutions. The need of these 2 groups - the network "sides" -to interact with each other efficiently has created the opportunity for the emergence of "platform intermediaries," third-party organizations that build client relationships by becoming trusted advisors, and act as open gateways to introduce corporations to a linked network of professionals.
} 
1. Evaluate client requests for proposals (RFPs) to determine the extent to which they reflect a desire for a solutions oriented program - this would involve assessing objectives (a clear determination of problems to be resolved/needs to be met); design (use of product/services and intellectual capital in meeting these objectives); metrics (quantification of short and longer-term outcomes resulting from program); the extent of program co-creation and evaluation with selected program provider.

2. Evaluate the business school's responses/proposal to explore how well they cover the designated areas of a well-designed program solution and if they demonstrate the unique capabilities required to deliver and replicate the solution.

Subsequent program-based activities are then assessed to see how well the initial program goals have been operationalized and, where necessary, adjusted to provide a strong integrated and longitudinal "solution" to the client's challenges.

\subsection{Case A - Global Management Development Program for European Semiconductor Manufacturer}

A brief overview of the program's design, delivery and performance measurement will be followed by an evaluation of the program using the building blocks described in the Solutions Roadmap (Figure 2). Although the Global Management Development Program (GMD) did not start by overtly pursuing a solutions-based architecture, it soon became clear to both client and supplier (a leading US business school) that the complex challenges of the semiconductor market required a highly tailored, co-created approach to executive education. ${ }^{10}$

The original Request for Proposal (RFP) for a customized Global Management Development Program comprised many of the elements often found in such documents:

- Current situation and challenges facing the company - e.g., fast industry growth and change in a global setting; a very young company (a spin-off from a corporate giant with the new company having an average employee age of 34 ) with a start-up spirit (despite having 32,000 employees).

- Target group: High potentials destined for top management positions

- Company goals/needs: included, in particular, that participants (mostly engineers) build a strong basis of integrated, cross-functional management knowledge while improving their entrepreneurial thinking.

- The GMD forms one of a portfolio of customized programs that forges a consistent view of management across the corporation.

\footnotetext{
${ }^{10}$ For a detailed description of both the conceptual philosophy and the operational execution of the GMD program see Dover, Lawler and Hilse, 2008.
} 
The business school response was to emphasize the following in their proposal and subsequent interactions:

- Become a thought partner with the client by gaining an abiding knowledge of both the strategy and culture of the corporation.

- Provide an integrated, cross-functional curriculum through the lenses of the entrepreneurial mindset. In the belief that the development and exploitation of business opportunities represents the ultimate entrepreneurial act, the program assessed the skills and resources required to take an idea from inception through to successful implementation.

- Juxtaposing rich, conceptual learning with pragmatic application of ideas to client needs. This was done, in large part, by action-based learning (the real-time evaluation of company specific opportunities) and customized case development (e.g., the acquisition of new/improved technology to facilitate market growth).

This highly client-driven approach allowed the business school to win the contract from three top-ten ranked executive education rivals who offered reputational excellence but limited customization.

Applying the Solutions Roadmap - the requirements of the GMD program very much lent it to a solutions-based perspective - a complex set of strategic and organizational challenges that needed external expertise to resolve, the availability of an outside provider with the intellectual property evident to problem solve, and the provision of program outcomes that offered measurable business value. Moreover, the early adoption of a solutions mindset allowed continuous program improvement and replication. In total, 15 3-week modules were run over a period of 8 years, involving the training of 450 high potential executives. Selected details of the program can be explored through the Roadmap areas of focus:

- Organizational Design - a) from the outset, the personnel involved in the ongoing program design and delivery were those directly responsible for company outcomes senior operational managers at the client and experienced, topic and industry knowledgeable faculty at the provider. The roles of company Human Resources and bschool Business Development and Program Management players remained secondary yet supportive throughout. b) various metrics were established to determine the longitudinal impact of the program on both participants and the company. Examples of these measurements were - i. post-program GMD participants were asked at 6-monthly intervals to reflect on the personal and corporate utility of program components (i.e., 
module content; action-based projects) ${ }^{11}$ ii. Two action-based projects were undertaken by cross-functional/regional teams during the program - the development of a plan for a business opportunity (e.g., identify market potential and competitive positioning for an active automobile driver assistance system such as night vision or lane departure warnings) and the assessment of a broad yet critical corporate issue (e.g., how to improve customer embeddedness in opportunity identification and project design). 60 business opportunities were analyzed with about $70 \%$ being pursued by the company. Of these roughly $85 \%$ have been implemented successfully with a few proving major revenue generators (e.g., e-passports; tire pressure monitoring). Similarly, 60 company issues have been explored with some being thought by senior management to have profound operational impacts (e.g., development of a scheme for M\&A process optimization). iii. Of the 450 high potential executives who participated in the GMD program, slightly more than $85 \%$ remained with the company after the final program iteration. These candidates were promoted more quickly than their peers due, in large part, to their careful selection, their expanded international network and their access to top management. c) having senior management involved not only in program design but in continuous program assessment, allowed for program goals to be modified over time. Whereas the objective of providing customized business knowledge for engineers remained unchanged, the importance of the following increased - ensuring real-world application of tools and techniques; an improvement of customer-oriented thinking; better networking between High Potentials and Top Management around the globe.

- Marketing Activities -- deep" knowledge of market trends and client needs are required to identify and design complex program solutions. Two ingredients are essential remarkable openness on behalf of the client to candidly reveal challenges faced and resources available, and a willingness on the part of the educator to spend considerable time and effort to reveal the "true" teaching and mentoring requirements. In the GMD case, two senior faculty members who had extensive prior experience of working with high technology companies spent two whole weeks in situ interviewing all Board members and senior executives, plus a sample of High Potential managers. ${ }^{12}$ Draft program designs were evaluated and improved by a small team of senior executives, who remained operational throughout the duration of the program. Consequently, continuous content improvement resulted from each program iteration (e.g., a number of custom cases were written to better understand, for instance, the management of disruptive technologies). Similarly, in-company adjustments were made resulting from

\footnotetext{
11 In fact, only two iterations of the 6-month assessment were carried out. It proved difficult to retain institutional momentum for continued measurement. Nevertheless, it was extremely useful to have a year's post-program feedback on content application.

${ }^{12}$ It is often difficult to get Executive Education clients to commit significant development funds to ensure design of highly tailored programs. This makes it important to distinguish "solutions" from other programs.
} 
program "discoveries." For example, an initiative entitled "Driving Customer-Oriented Innovation" was instigated to allow business opportunity activity to be more target focused while improving time to market for new products.

- Portfolio Management -- as a multi-billion dollar company, the semiconductor manufacturer ran an extensive stable of management training and executive education programs. The majority of these could be considered as "traditional" where knowledge was imparted and skills developed (finance, marketing, leadership) using relatively short, stand-alone interventions. Although most programs were "off the shelf," a number were tailored to meet specific needs (e.g., Marketing for High Technology Products). However, even with the latter there was limited commitment to higher-order solutions design (i.e., fastidious partner co-creation; continuous senior management involvement in design and program improvement; goal assessment through short and longer-term program evaluation). Within this setting, the GMD program assumed a special significance. While initially envisaged as a customized executive education program pursuing goals such as providing sector relevant business knowledge for engineers it quickly morphed into an integral component in the strategic advancement of the organization. By bringing together the best and the brightest of high potential employees, it became possible to expose them to the latest strategic and operational concepts, have them apply these concepts to critical real-world issues facing the company, provide them with extensive intellectual exposure to senior executives and board members, and build a global network of similarly well-trained managers who could now view opportunities from an informed and non-parochial perspective. More importantly, these benefits were embraced by senior decision makers and incorporated into the modus operandi of the company. The 15 cohorts of program participants became ambassadors within the organization, establishing a common business vocabulary, inculcating an opportunity driven mindset, and acting as mentors for junior staff. $^{13}$

- Sales and Sales Enablement - although the semiconductor client was committed from the outset to create a highly customized executive program that met certain important needs in a volatile industry (e.g., allow engineers to understand business process thinking; build a global network among participants; attract interesting candidates and retain key employees), it was the further insights of visionary company leaders and imaginative personnel at the business school that allowed a broader solutions perspective on learning to emerge that probed deeper into organizational and individual requirements. Participants would "graduate" from GMD not only with a deep

\footnotetext{
${ }^{13}$ Since completing the GMD program, the semiconductor manufacturer has performed well in a highly competitive market. Over the past 5 years, revenues have expanded by about $40 \%$ while net income in 2015 stood at almost $10 \%$.
} 
knowledge of conceptual tools, but the ability to apply them to specific business development opportunities and to broader corporate challenges (see earlier section on action-based learning). In order to avoid the leaky bucket syndrome ${ }^{14}$, class members were tracked following the program to determine their application of tools, their pursuit of entrepreneurial initiatives and their building of strategic employee networks. What allowed the GMD sales process to transform the program into a "customer specific solution" (see Figure 1)? Major contributing factors included the following:

(1) Because of the complexity of the business challenges facing the client, an integrated sales team approach was taken by the business school. This comprised business development personnel, subject-expert faculty and senior administrators (e.g., Dean of Executive Education). The key player here was the faculty director ${ }^{15}$, appointed on receipt of the RFP, who orchestrated each phase of the decision making process and subsequent program activities. He/she "acted as a quarterback" within the sales team, guiding and influencing the client through their "customer decision journey" (Court et al, 2009) by ensuring that the correct human and IP resources were available at each stage.

(2) To have the GMD program viewed inside the company as a solutions-driven activity required significant "sales" involvement by selected senior executives. This demanded not only co-creation of course content with faculty members but careful consideration of how course output would be pragmatically operationalized, including the persuasion of management skeptics to fully utilize course concepts. This process was made easier by the active endorsement of the CEO throughout the program. For example, he (and his Board) attended all business opportunity presentations, providing further "venture capital" funding for promising new ideas. Similarly, each participant group attended a Board meeting to present their findings on major company issues (e.g., improving customer embeddedness). A Board Member was allocated to "champion" each promising team viewpoint.

- Culture and Behavior - A recent study revealed that "people" rather than process or technology constituted the greatest challenge to creating and implementing solutions. $39 \%$ of B2B participants in a recent survey found "changing our culture and behavior to match our solutions strategy" provided the most difficulty in pursuing solutions-related

\footnotetext{
${ }^{14}$ The Leaky Bucket Algorithm is based on, and gets its name from, the analogy of a bucket that has a hole in the bottom through which any water (knowledge) contained will leak away at a constant rate, until it is either empty or until it is reinforced or replenished. In the case of learning, it is felt that early application/reinforcement of knowledge (e.g., through action-based learning) will counteract leakage and eventually lead to memory assimilation.

${ }^{15}$ Building longitudinal relationships with clients, especially those involving a solutions-based approach, is a resource intense pursuit. In such circumstances, we would argue that key faculty should be seconded from regular academic pursuits (e.g., undergraduate and graduate teaching) to give their full attention to the acquisition and retention of successful executive programs.
} 
activity (Schwartz and Hurley, 2012). We would argue strongly that the same human barriers exist in adopting a solutions-based approach to executive education. Some of the actions taken to mitigate such problems in the GMD program were as follows:

a) It was understood that, in the final analysis, the client wishes to retain control of major decisions relating to the development of the educational solution (see Schwartz, Dover and Perkins, 2004). Despite the subject expertise available to the supplier, the complex knowledge problems belong to the client with the result that senior management should insist on involvement in all aspects of the design and delivery processes. Far too many executive education programs have foundered on the business schools "I know what's best for you" attitude, with resultant sophisticated learning materials failing the problem relevance test. Educators must support the co-creation of solutions, with hopefully - over time - becoming "trusted partners" and even thought leaders (being asked to research/consult on critical company issues) with the client.

b) The modern business school should work more as a network entity than as a classical free-standing organization with its own academic departments (Lorange, 2005). This approach will be reflected in solution program design. In GMD an open system was employed in which appropriate faculty were found from inside and outside the business school, senior executives provided candid in-program insights on initiatives and challenges within the company and its broader industry, and even key accounts were invited to the classroom to provide the customers view on corporate performance.

c) Changing culture and behavior requires unremitting and inspirational communications. In GMD these took many forms. Top executives spoke regularly on important and emerging topics (e.g., the adoption of value-based pricing for innovative logic semiconductor products), Board Members held informal, "fireside" chats at each program, a web-site was created to keep participants and other employees informed on program developments and outcomes (e.g., the commercial results of the business opportunity projects) and the faculty ran a number of alumni presentations to keep participants current on evolving business trends (for instance, a session on aligning strategy and implementation attracted 160 employees). Finally, as the program aspired to create global knowledge and cultural sensitivity, delivery was initially conducted in both Europe ( 2 weeks) and the US ( 1 week). About half-way through the 15 program period, it was decided to replace one of the European weeks with a week in China, given its growing cultural and commercial importance.

Although we have taken a post-hoc approach to considering a highly customized executive education program within an extant solutions-based framework, we have found strong a priori 
support that program classification on a solutions continuum (Figure 1) and the application of the five drivers of solutions mastery (Figure 2) offers valuable guidelines on the design, delivery and measurement of complex knowledge interventions. We did have the benefit of the first author consulting extensively with mainly technology-based clients on building solutions capabilities within their product and service organizations and therefore being able to see the merits of applying many of these tenets - often in a somewhat ad hoc fashion -- to the evolving GMD program. Nevertheless, as we look ahead, it would be highly instructive to have a client with complex educational needs, partnered by a suitably adept IP provider, systematically apply and further adapt the Solutions Roadmap to provide a productive and measurable learning experience from idea inception through to program impact (hopefully, including quite some time after termination). The final section provides some recommendations as well as caveats to employing a solutions-based approach to the world of executive education.

\section{IMPLICATIONS OF FINDINGS FOR BUSINESS SCHOOLS}

To employ a solutions-based approach to executive education program design we believe the following three characteristics must be present:

a) a complex learning problem that the client company is unable (or unwilling, with current resources) to resolve

b) proven expertise/IP within the business school (and its internal/external partners) to "solve" the problem

c) appropriate measurement metrics that allow for both the short and longer-term determination of program performance in goal attainment

It becomes quickly clear that not all executive education programs lend themselves to a solutions methodology. It is a costly and time consuming approach and is only warranted in certain situations ${ }^{16}$. Some of these are as follows:

- Replicability -- although a complex solution is designed for a "client of one," it is important that the solution can be largely replicated for the same client or for other, similar clients (i.e., multiple clients of one!). Because the initial solution is so resource intense and consequently expensive, costs must be recouped in at least 2 ways $-i$ ) building a strong relationship with the initial client so that the program is repeated many times within the company, and ii) the solution can be tailored for other similar

\footnotetext{
${ }^{16}$ There is an interesting analogy between choosing to use "solutions' and the application of "value based pricing" (Dolan,2003). The latter should preferably only be employed when a) new products/services are being introduced, b) the potential market value of the product/service is large, and c) the company possesses a clear and desirable point of differentiation. Indeed, value based pricing could be a preferred approach to solutions pricing.
} 
clients (e.g., within the same vertical industry) using the $80 / 20$ rule - that is, $80 \%$ of program content is largely standardized while $20 \%$ is customized to specific client needs.

- Customer choice - the best customers for solutions may not be current customers for existing executive education programs. Such clients are likely to have become used to more traditional offerings and be reluctant to pay premium prices for unproven solutions. An alternative target could be upstart, innovative companies that have no established b-school loyalties and are open to productive, long-lasting partnerships. For instance, aggressive market followers aiming to disrupt leaders in a volatile growth market (e.g., medical devices) may be receptive to highly focused, experimental solutions that aim to keep executive capabilities ahead of competitors.

- Delivered value - agreed credible success measures may be the best way of persuading a potential client to undertake the hard, preparatory work required to create a solutions-oriented environment inside the company as well as pay a price premium for the educational offering. We mentioned some possible ROI measures earlier in the article. We could even imagine the b-school having some financial "skin-in-the-game" with remuneration being linked to program outcomes (e.g., success of action-based projects). ${ }^{17}$ A variant approach is value evolution - where customers are actively involved in the design (and delivery) of the program, they are likely to be more forgiving of less-than-stellar early efforts and willing to take a more supportive role toward steadily delivering increased value. An example from the second author comes from a consulting company now on its $10^{\text {th }}$ program cohort, involving over 200 senior delegates to date, where the first delivery was particularly challenging but sufficiently innovative that commitment was made to continuously evolve the joint design and delivery. As a result, the delivered value has increased substantially over time.

Solutions are tricky. Early research by Mckinsey (Foote et al., 2001) revealed that three out of four companies showed little gain from developing and marketing solutions. We must therefore work hard to improve this probability of success when investing in solution platforms to build executive education programs. Our experience to date suggests that the following considerations will help in achieving this goal:

1. Client collaboration. A solution provider (in this case the business school) engages in long term collaboration, and co-creates value with the customer (see Starbacka, 2011). This requires the establishment of relational processes in both supplier and client. For instance, the role of a highly focused and flexible faculty team led by one or more

\footnotetext{
17 "Performance-based pricing" ties what the customer pays directly to the economic value received and the incremental cost to serve (Shapiro, 2002). While this is extremely difficult to quantify in the provision of a service such as an executive education program, it would be possible to have payment gradations based on levels of client satisfaction with measured program results.
} 
dedicated and knowledgeable faculty directors was essential to build the position of "thought partner" and eventually "thought leader" with the client. Similarly, the presence of continuous formal (a group of senior company managers who worked on program design and continuous content improvement) and informal (Board level personnel who made regular program appearances and evaluated project outcomes) executive groups ensured on-going dialogue both inside the company ("are we getting the value-in-use desired?") and with the business school ("can we adjust topics to improve company relevance?").

2. Cross-functional cooperation. Because the problems faced by firms considering a solutions-based approach to executive development are complex and multi-dimensional (e.g., preparing engineers to become general managers in a volatile, fast-changing world), the solutions framework becomes cross-functional in nature. This may require the redefinition of boundary spanning roles involving intra- and inter-organizational functions. The faculty director, for instance, will need to rely on more than his/her expertise on, say, strategy to become a "quarterback" for managing the interface of a team of subject experts with their corporate equivalents. This resonates with the call for new types of professionals, often called ''t-shaped,' as they have deep problem solving skills in one discipline .... as well as broad communication skills across many disciplines" (Starbacka, 2011).

3. Management of risk. The engagement with clients to take a solutions perspective on educational challenges can entail higher cost and risk levels to the business school compared to selling more traditional executive programs. First, then, it becomes of utmost importance that the decision to adopt a solutions business model is strategically supported by top management at both supplier and client. Second, it is necessary to appreciate the changing risk profile of the provider. For example, the risks may relate partly to being responsible for customers' process performance (e.g., outcomes from business opportunity projects) that require quantitative measures that go far beyond the regular, end-of-program satisfaction scores. If a business school wishes to make the investment in the transition to a solutions model, it must take into account the appropriate risks and returns when creating a business case. Some of this may be alleviated through adopting a pilot program in a clear solution setting (such as steps $d$ ) and e) in Figure 1) with a responsive client.

4. Building Segment Solutions Capability. The business school management system should move beyond the shackles of functional thinking, perhaps organizing around challenging customer segments (e.g., health care) as a key starting point. As a school organizes around segments, it accumulates knowledge about the sector (players, environment, etc.), allowing it to build solution-oriented value propositions that resonate with potential clients within the segment. The implementation of successful solution 
programs generates added intelligence and allows the creation of standardized solution elements, thus encouraging both program replication and scalability.

Our deliberations lead to the recommendation that business schools move beyond selling and delivering ad-hoc solutions. While our work with the semiconductor company started as an opportunistic venture, deep and continuous collaborative work by both parties allowed measurable solutions to evolve that exceeded program goals. If solution mastery is achieved, business schools will have a competitive advantage that is difficult to match.

Given the caveat that only a relatively small number of executive programs may lend themselves to the rigors of a solutions-based approach, ${ }^{18}$ it is felt that the development of a solutions infrastructure is warranted in business schools that see customized education as an integral component in their delivery system. Such schools require evidence of capabilities in a) strategic planning (e.g., identifying focused markets for solutions business), b) management systems (e.g., cross-functional roles and responsibilities of a "solutions champion,") and c) infrastructure support (e.g., specialized people for gathering business intelligence on high profile prospects). These platform components should allow systematic monitoring of the business-school performance with individual customers and chosen market segments.

We are excited by the application of an imaginative Solutions Competency Model to the world of executive education. We are unaware of any prior explicit attempt having been made to import the solution concept in this way. We believe our experience with the semiconductor company strongly suggests the benefits that a systematic, disciplined approach to program development and implementation might bring. We are conscious, however, that we are at the very beginning of an intellectual journey. Can our solutions roadmap be adapted to better aid business schools resolve the challenges of complex client problems? Are business schools already successfully providing measurable, long-term, collaborative guidance to major customers without using the buzzword "solutions?" How can we translate the solutions model for application to the burgeoning on-line executive education market? We invite pedagogical researchers to weigh in on this topic by sharing their opinions and experiences.

\footnotetext{
${ }^{18}$ Research on the commercial application of solutions to products/services (Schwartz and Hurley, 2012) suggests that no more than $10-20 \%$ of projects warrant this approach.
} 


\section{Appendix A}

\section{The ITSMA Solutions Roadmap: Stages in the Evolving Solutions Process}

Level 1. Opportunistic Solutions - There is no consistent process for solutions development and delivery at this point. Solutions are developed in an ad hoc fashion in response to serendipitous opportunities from clients and prospects

Level 2. Solutions Repeatability - After seeing success with individual solution implementation, the organization begins to look at ways to consolidate and reuse the solutions IP developed for those projects. Change management becomes an issue at this point. For a solutions strategy to scale successfully, a larger portion of the organization must become regular contributors to the solutions development and delivery process.

Level 3. Coordinated Planning -- Organizational commitment to a solutions strategy grows with the establishment of a permanent group to foster development of solutions, crossorganizational cooperation, and alliances with outside providers to contribute components of solutions. Coordinated planning and widely applicable solutions development and delivery processes begin to emerge, driven by the need for solutions to become repeatable and scalable.

Level 4. Process Excellence - Formal, structured processes emerge for cross-functional cooperation and solutions development.

Level 5. Solutions Mastery - Solutions processes are institutionalized inside the organization. Solutions are embedded in the research and development processes of the company/institution. Products and services are developed with solutions in mind, using standard interfaces that enable them to be assembled into solutions with minimal effort. Source: ITSMA, 2009 http://www.itsma.com/solutions/solutions-roadmap/ 


\section{Appendix B}

The Phillips Model for Evaluating Human Resource Development and Training

The Phillips ROI Methodology is considered the most credible and widely used way to forecast the potential payoff - ROI - of a proposed training or human development initiative.

Level Brief Description

1. Reaction, Satisfaction \& Planned Action

2. Learning

3. Application and Implementation

4. Business Impact

5. Return on Investment (ROI)
Measures participant reaction to and satisfaction with the training program and participant's plans for action Measures skills and knowledge gains Measures changes in on-the-job application, behavior change, and implementation

Measures business impact

Compares the monetary values of the business outcomes with the costs of the training program

Source: www.roiofcoaching.com/kirkpatrick-phillips-evaluation-model.pdf 


\section{REFERENCES}

Jamie Anderson and Gert-Jan van Wijk, "Customizing Executive Learning: A Business Model for the Twenty-First Century," Journal of Management Development, Vol. 29, \# 6, 2010, 545 - 555. Josh Bersin, "Spending on Corporate Training Soars: Employee Capabilities Now a Priority," Forbes, Feb 4, 2014.

Ben Carroll, Raju Singaraju and Eunyun Park, "Corporate Learning Handbook 2015: Benchmarks, Trends and Analysis of the US Training Market," Bersin by Deloitte, 2015.

David Court, David Elzinga, Susan Mulder and Ole Jørgen Velvik, "The Consumer Decision Journey," McKinsey Quarterly, June, 2009.

Andrew Davies, Tim Brady and Michael Hobday, "Charting a Path Toward Integrated Solutions," MIT Sloan Management Review, Vol. 47, Issue \#3, Spring, 2006, 39-48.

Niraj Dawar, "When Marketing is Strategy," Harvard Business Review, December, 2013.

Robert Dolan, "Pricing: A Value-Based Approach," Harvard Business School, 9-500-071, November, 2003.

Philip Dover, William Lawler and Heiko Hilse, "Creating an Entrepreneurial Mindset at Infineon Technologies," Journal of Change Management, Vol. 8, \# 3-4, September-December, 2008, 265277.

Philip Dover and Julie Schwartz, "Are Solutions the Solution to Adding Customer Value?" Proceedings of the $1^{\text {st }}$ International Conference on Management, Leadership and Governance, ACPI, Bangkok, Thailand, 2013.

Nathaniel Foote, Jay Galbraith, Quentin Hope and Danny Miller, "Making Solutions the Answer," McKinsey Quarterly, 2001.

Ranjay Gulati, "Silo Busting: How to Execute on the Promise of Customer Focus," Harvard Business Review, May, 2007.

Donald Kirkpatrick and James Kirkpatrick, "Evaluating Training Programs," Berrett-Koehler Publishers, 1994.

Peter Lorange, "Strategy Means Choice: Also for Today's Business School!" Journal of Management Development, 2005, Vol. 24, No. 9, 783-790. 
A. Maira and Chris Koch, "How to Organize Your Company to Deliver Solutions: ITSMA's Solutions Organizational Integration Model," ITSMA Update, July, 2009.

Jack Phillips, Return on Investment in Training and Performance Improvement Programs, $\left(2^{\text {nd }}\right.$. Edition), Butterworth-Heinemann, Burlington, MA, 2003.

Kaj Storbacka, "A Solution Business Model: Capabilities and Management Practices for Integrated Solutions," Industrial Marketing Management, Vol. 40, 2011, 699-711.

Sandra Swanson, "Measuring ROI on Executive Education: It Can Be Done," Crain's Chicago Business, January 29, 2011.

Julie Schwartz, Philip Dover and Sam Perkins, "IT Solutions: The Customers' Turn to Speak," Babson Executive Education Insight, 2004.

Julie Schwartz and Stephen Hurley, "Anatomy of a Solutions Marketer," ITSMA/Solutions Insight Online Survey, February, 2012.

Benson Shapiro, "Performance-Based Pricing is More than Pricing," Harvard Business School Industry Note, 2002.

The Association of Talent Management (ATA) State of the Industry, 2013.

Kapil Tuli, Ajay Kohli and Sundar Bharadwaj, "Rethinking Customer Solutions: From Political Bundles to Relational Processes," Journal of Marketing, Vol. 71, (3), July 2007, 1-17.

Michael Tushman, Charles O'Reilly, Amy Fenollosa, Adam Kleinbaum and Dan McGrath, "Relevance and Rigor: Executive Education as a Lever in Shaping Practice and Research," Academy of Management Learning and Education, 2007, Vol. 6, No. 3, 345-362. 